\title{
EDITORIAL
}

\section{Headache Medicine: a new star is appearing on the horizon}

Dear friends,

Headache Medicine is a medical specialty that is attracting neurologist, neurosurgeons, pain specialists and basic researchers. The United Council of Neurologic Subspecialist (UCNS) considered Headache Medicine as a subspecialty concerned with the diagnosis and treatment of headache and face pain. A great expansion has been occurring in the field of Headache Medicine during the recent years, manifesting in a substantial increase in scientific publication in this area (Figure 1). We could enumerate several different facts related with this mentioned booming success, among then surely the creation of both the American Headache Society (1959) and the International Headache Society (1981) were very important. A similar phenomenon occurred in our country with the foundation of the Brazilian Headache Society (1978, see Figure 1). Another point of importance is the existence of good scientific journals in the field of Headache Medicine (e.g. Cephalalgia, Headache, Journal of Headache and Pain, among others). In the past, a great number of Brazilian articles in the area of headache were published in Neurobiologia (1938), Arquivos de Neuro-Psiquiatria (1943) and Migrâneas \& Cefaléias (1994-2009). We wish that the publication of this new Brazilian Headache Journal - Headache Medicine - will further stimulate the growth and development of our Brazilian Headache Society and spread new understanding and ideas in the magnificent branch of learning of Headache and Pain Medicine.

words: Headache Brazil (PubMed)

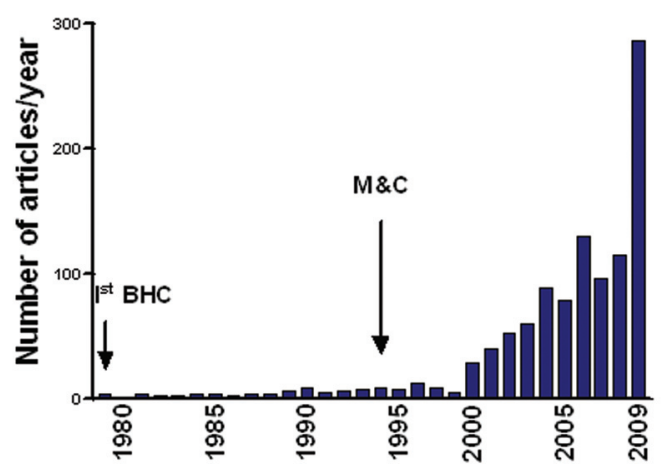

word: Headache (PubMed)

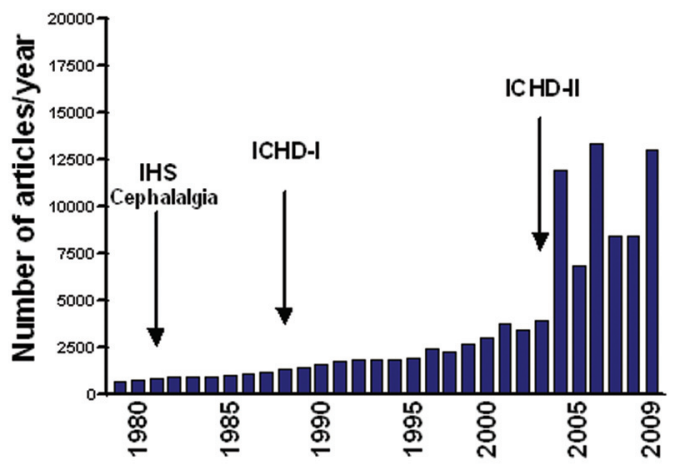

Figure 1. Number of articles published per year encountered in PubMed with the words "Brazil and/or headache". Ist BHC, First Brazilian Headache Congress; M\&C, Migrâneas \& Cefaléias; IHS, International Headache Society; ICHD, The International Classification of Headache Disorders.

Marcelo M. Valença, Fernando Kowacs 